ZOOLOGIA 31 (5): 482-488, October, 2014

http://dx.doi.org/10.1590/S1984-46702014000500008

\title{
Ceracis zarathustrai sp. nov. (Coleoptera: Ciidae) from the Atlantic Forest biome
}

\section{Ítalo S.C. Pecci-Maddalena ${ }^{1,4}$, Vivian Eliana Sandoval-Gómez² \& Cristiano Lopes-Andrade ${ }^{3}$}

\author{
1 Programa de Pós-graduação em Entomologia, Departamento de Entomologia, Universidade Federal de Viçosa. \\ 36570-900 Viçosa, MG, Brazil. \\ 2 Programa de Licenciatura em Biologia, Universidade Federal do Tocantins, Campus Araguaína, 77838-824 Araguaína, TO, \\ Brazil. \\ ${ }^{3}$ Laboratório de Sistemática e Biologia de Coleoptera, Departamento de Biologia Animal, Universidade Federal de Viçosa, \\ 36570-900 Viçosa, MG, Brazil. \\ ${ }^{4}$ Corresponding author. E-mail: italopecci@gmail.com
}

\begin{abstract}
Ceracis Mellié, 1849 is the second most speciose genus of Ciidae, with 51 described species. Here we describe Ceracis zarathustrai sp. nov. based on adult individuals collected in three remnants of the Atlantic Forest biome (states of Minas Gerais and Espírito Santo). We provide information on its host fungi and briefly discuss the morphological affinities with other species of the genus.
\end{abstract}

KEY WORDS. Brazil; ciid; Ciinae; minute tree-fungus beetles; Neotropical.

Ceracis was described by Meluté (1849) as a subgenus of Ennearthron Mellié, 1847. LACORDAIRE (1857) elevated Ceracis to genus and then LAWRENCE (1967) redefined its limits. Currently, Ceracis encompasses 51 described species, being the second most speciose genus of Ciidae (Antunes-Carvalho \& LopesAndrade 2011, 2013). Considering both described and undescribed forms, Ceracis is more diversified in the New World, but there are several species occurring in Oceania and islands of the Pacific Ocean, and two in the Palearctic region. Two Ceracis have been recognized as invasive species (AnTunesCarvalho \& Lopes-Andrade 2013): C. cucullatus (Mellié, 1849), native to the continental South America and introduced in Galapagos, and C. tabellifer (Mellié, 1849), native to the Neotropical region and introduced in Africa and south and southeast of Asia. At least twelve described species of Ceracis occur in Brazil, as follows: C. bicornis (Mellié, 1849), C. cassumbensis Antunes-Carvalho \& Lopes-Andrade, 2011, C. cornifer (Mellié, 1849), C. cucullatus, C. lamellatus (Pic, 1939), C. tabellifer, C. furcifer Mellié, 1849, C. limai Lopes-Andrade et al., 2002, C. nigropunctatus Lawrence, 1967, C. ruficornis Pic, 1916, C. simplicicornis (Pic,1916), and C. variabilis (Mellié, 1849).

Species of Ceracis have oval to elongate body, antennae with 8 to 10 antennomeres, prothorax with narrow sides and obtuse to rounded anterior angles, prosternum concave with posterior process laminate, protibia apically expanded and bearing several spines along the outer apical angle, metaventrite strongly convex, the discrimen short or absent, and vestiture consisting of very short and fine setae, usually inconspicuous. Males have a sex patch at the middle of the first abdominal ventrite, a common feature to most male Ciinae, and usually have conspicuous horns or tubercles at both pronotal apex and frontoclypeal ridge (LAWRENCE 1967).

Four species-groups were defined for the genus ( $C$. cucullatus, C. furcatus, C. furcifer, and C. singularis), but they encompass only 21 species (LAWRence 1967, Lopes-ANDrade et al. 2002). These groups are based exclusively on external anatomical similarities of the species and leave 30 species without group assignment.

Our objective in this work is to describe Ceracis zarathustrai sp. nov. (Ciinae) and to provide information on its host fungi and geographic distribution. This new species does not fit in any of the four defined species-groups of Ceracis and is known only from remnants of the Atlantic Forest (states of Minas Gerais and Espírito Santo).

\section{MATERIAL AND METHODS}

Three paratypes were dissected, being one male and one female from Viçosa (Minas Gerais) and one male from Tiradentes (Minas Gerais) in southeastern Brazil. The holotype was not dissected. Images of dissected sclerites are of paratypes. Terms for external morphology and male terminalia of ciids follow LopesANDRADE \& LAWRENCE $(2005,2011)$; controversial terms common in the taxonomy of Ciidae are detailed explained there. Description of male frontoclypeal horn follows OLiverRa et al. (2013). The term "single" refers to the punctation consisting of uniformly-sized punctures following the usual nomenclature in taxonomic works on Ciidae (e.g., LAWRenCE 1971, Lopes-ANDRADE 
\& LaWrence 2005, Lopes-Andrade 2011). The following symbols are used for measurements (in $\mathrm{mm}$ ) and ratios: (BW) basal width of the scutellum; (CL) length of the antennal club (measured from base of the seventh to apex of the ninth antennomere); (EL) elytral length (at midline, from base of scutellum to elytral apex); (EW) greatest elytral width; (FL) length of the antennal funicle (measured from base of the third to apex of the sixth antennomere); (GD) greatest depth of the body (from elytra to metaventrite); (GW) greatest diameter of the eye; (PL) pronotal length along midline; (PW) greatest pronotal width; (SL) longitudinal length of the scutellum along midline; (TL) total length (= EL + PL, head not included). The ratio GD/EW was recorded as an indication of degree of convexity; TL/EW indicates degree of body elongation.

Labels were printed on white paper, unless otherwise specified between square brackets. Pin label transcriptions are placed within quotations marks, with each label separated by a backslash. The number and gender of specimens bearing these labels are stated immediately before the label data.

Specimens were studied, measured and photographed under a Zeiss Discovery V8 stereomicroscope equipped with a Zeiss Axiocam MRc digital camera. Final images of the body were the result of joining about 30 slices at different focal lengths using the extended focus module of Zeiss Axiovision 4.8 software. Whole mount preparations of male terminalia followed the protocol described by LOPES-ANDRADE (2011) and photographies of dissected sclerites were made under a Zeiss Axiolab optic microscope equipped with a Zeiss Axiocam ERc $5 \mathrm{~s}$ digital camera. We estimated latitude and longitude coordinates by tracking localities in the online database Geo-Names (WICK 2010) and plotted them onto a map. The specimens were deposited in the following institutional collections (with acronyms used in this paper): (CELC) Coleção Entomológica do Laboratório de Sistemática e Biologia de Coleoptera, Universidade Federal de Viçosa, Viçosa, Minas Gerais; (MCNZ) Museu de Ciências Naturais da Fundação Zoobotânica, Porto Alegre, Rio Grande do Sul.

\section{TAXONOMY}

\section{Ceracis zarathustrai sp. nov.}

Figs 1-10

Type-locality. "Mata da Biologia", a remnant of regenerated Atlantic Forest at the campus of the Federal University of Viçosa, in Viçosa, southern portion of the state of Minas Gerais, southeastern Brazil (2045.337'S 42 $\left.51.657^{\prime \prime} \mathrm{W}\right)$.

Diagnosis. Body elongate (TL/EW 2.13-2.38), glabrous dorsally. Elytral punctation single and dense. Males with frontoclypeal ridge strongly produced, forming a long and narrow, strongly elevated, subcylindrical median horn, which is subtruncate and bears a conspicuous tuft of yellowish bristles at apex; anterior edge of pronotum varying from strongly pro- duced forward, forming two rounded lateral lobes, to weakly or not produced, with its anterior edge almost rounded; first abdominal ventrite with a broad, transversely oval setose sex patch (Fig. 5, arrow).

Description, male holotype (Figs 1-5). Adult apparently not fully pigmented but in good condition. Measurements (in mm): TL 1.51, PL 0.58, PW 0.64, EL 0.93, EW 0.66, GD 0.61. Ratios: PL/PW 0.91, EL/EW 1.41, EL/PL 1.60, GD/EW 0.92, TL/ EW 2.29. Body glabrous, elongate, subcylindrical, shiny; dorsal surface mostly dark reddish-brown; ventral surface reddishbrown, except for yellowish-brown metaventrite; basal antennomeres, mouthparts and legs mostly yellowish-brown; antennal funicle and club reddish-brown. Head barely visible from above; dorsal surface immediately above horn base concave, glabrous, sparsely punctate; frontoclypeal ridge strongly produced, forming a long and narrow, upward directed subcylindrical median horn (length $0.3 \mathrm{~mm}$; width $0.12 \mathrm{~mm}$ ), thicker at base than at apex, strongly tumid at middle, with apex subtruncate and bearing a conspicuous tuft of yellowish bristles. Antennae (left antenna measured) with FL $0.07 \mathrm{~mm}$, CL $0.17 \mathrm{~mm}, \mathrm{CL} / \mathrm{FL} 2.43$, length of antennomeres 1-9 (in mm) as follows: $0.05,0.05,0.03,0.02,0.01,0.01,0.05,0.05,0.07$; each antennomere of the club bearing several scattered slender setae and four conspicuous sensillifers positioned at its upper portion. Eyes coarsely facetted, with minute slender yellowish setae emerging from the intersection between ommatidia, GW $0.11 \mathrm{~mm}$. Pronotum subquadrate, with anterior portion produced forward, covering head; anterior edge shallowly emarginated and forming two short and rounded lateral lobes; sides narrow, not visible from above; posterior edge sublinear, punctation fine, single, uniformly distributed; distance between punctures from 2.5 to 5 puncture-widths; each puncture bearing a yellowish decumbent minute seta, barely visible even at a magnification of 80x; in between punctures shiny, microreticulate. Scutellum small, triangular, with few punctures, each one bearing a short, fine, decumbent setae; BW $0.13 \mathrm{~mm}$ and SL $0.07 \mathrm{~mm}$. Elytra about $1.5 \mathrm{x}$ as long as pronotum; sides subparallel at the basal two-thirds, then abruptly converging toward apex; punctation single, denser than pronotal punctation; punctures irregular, coarser and deeper than those on pronotum; vestiture similar to that of pronotum, but in between punctures smooth and shiny; humeral calli conspicuous. Hind wings developed, apparently functional. Prosternum in front of coxae shallowly biconcave; prosternal process laminate, almost as long as coxae and projected bellow prosternal disc. Protibia with outer apical angle rounded and bearing a row of spines; apex expanded. Meso and metatibia without spines on outer apical angle. Metaventrite moderately convex, subglabrous, bearing scattered slender setae; surface microreticulate; discrimen short but discernible (Fig. 3). Abdominal ventrites with microreticulate surface, shallow punctures and scattered slender setae, longer than those on dorsal surface; length of ventrites 1-5 (in mm, 

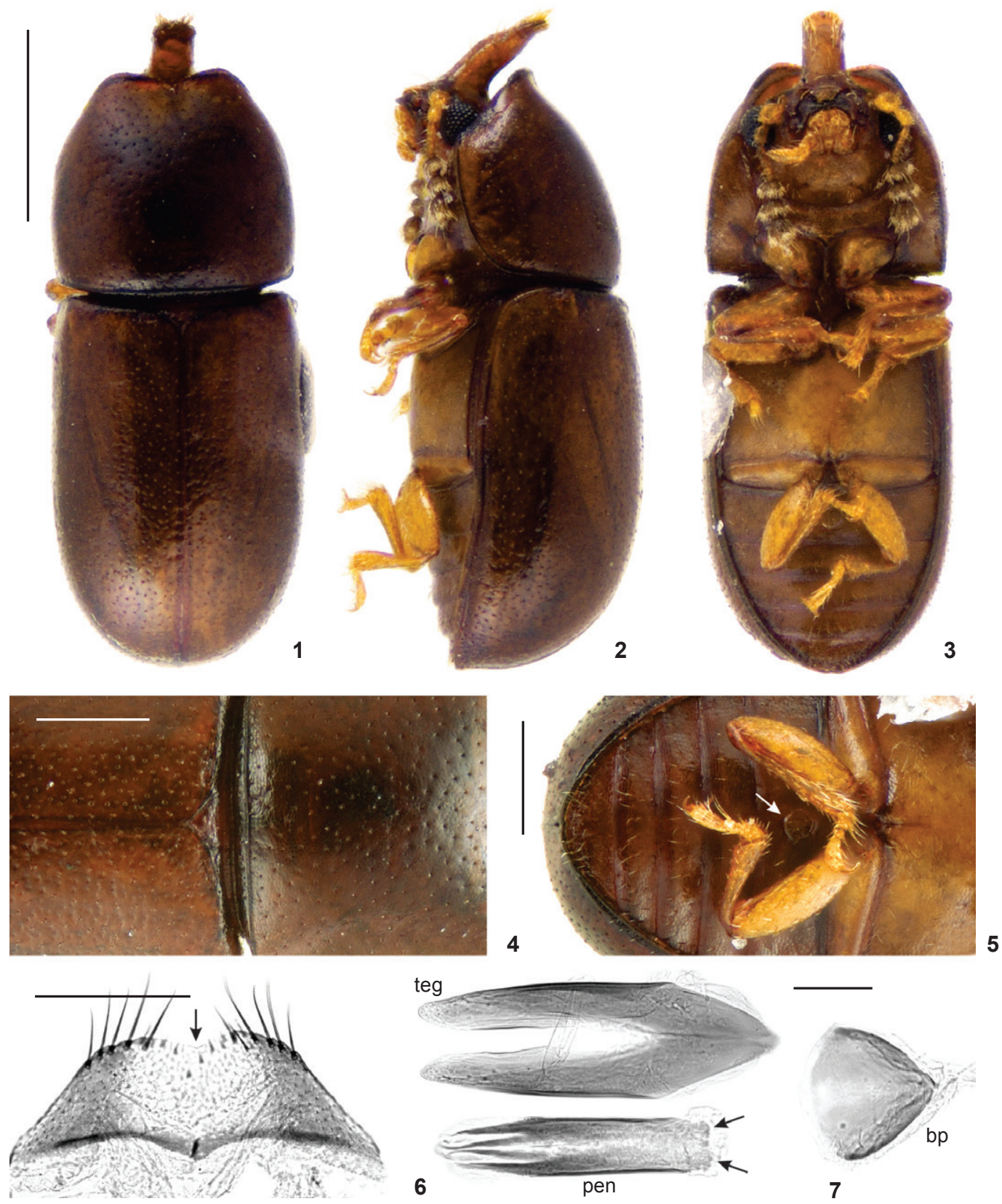

Figures 1-7. Ceracis zarathustrai sp. nov. : (1-5) adult male holotype : (1) dorsal view; (2) lateral view; (3) ventral view; (4) detail of the dorsum, showing the denser pronotal punctation of elytra and the comparatively finer punctation of pronotum; (5) sex patch (arrow) at the first abdominal ventrite; (6-7) dissected terminalia of a paratype: (6) sternite VIII, showing the short concave emargination at middle of posterior margin (arrow); (7) tegmen (teg), penis (pen) showing blunt basal edge (arrows), basal piece (bp). Scale bars: 1 $3=0.5 \mathrm{~mm}, 4-5=0.2 \mathrm{~mm}, 6-7=0.1 \mathrm{~mm}$.

from base to apex of each ventrite at longitudinal midline): $0.16,0.09,0.09,0.08,0.08$. First abdominal ventrite bearing a circular, marginated, pubescent sex patch at center (Fig. 5, arrow), with a transverse diameter of $0.05 \mathrm{~mm}$. Male terminalia (paratype, Figs 6 and 7) with sterniteVIII with posterior edge bearing a short concave emargination at middle (Fig. 6, arrow); posterior corners rounded, bearing bristles; lateral edges diverging from posterior to anterior portion; anterior edge bi- 

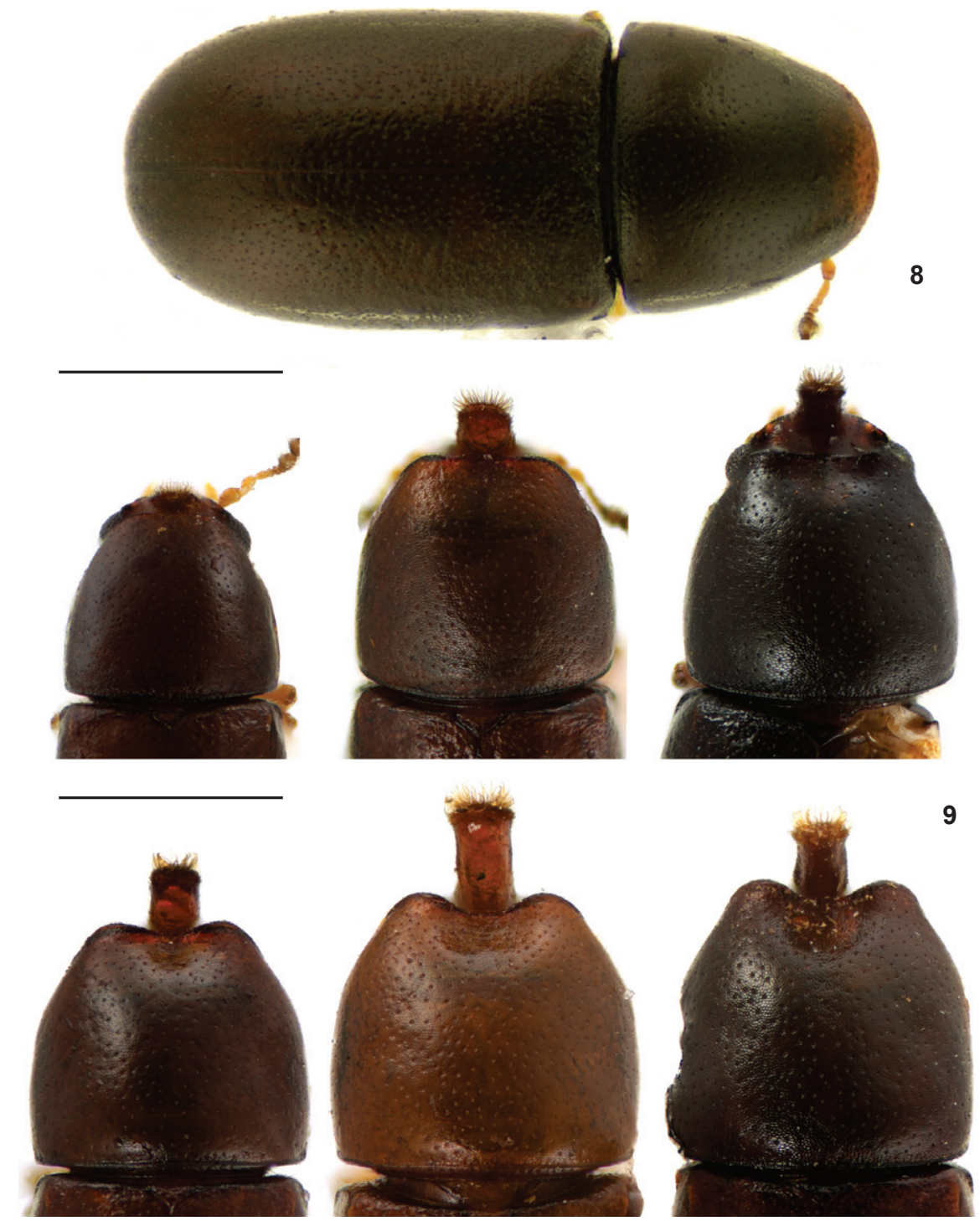

Figures 8-9. Ceracis zarathustrai sp. nov.: (8) female; (9) differences in development degree of the anterior edge of pronotum between males. Scale bars: $0.5 \mathrm{~mm}$.

concave, rounded and slightly sclerotized at middle, but not forming a strut. Basal piece (Fig. 7) subtriangular, membranous, with rounded sides and about as wide as long. Tegmen (Fig. 7) slightly longer than and twice as wide as penis; basal portion subtriangular; basolateral edges thick; lateral edges subparallel at their basal half and then slightly converging to apex; apex of each lateral edge bearing some sensilla. Penis (Fig. 7) elongate, subcylindrical; basal edge blunt (Fig. 7, arrows); sides subparallel at basal two-thirds, with sclerotized apical third converging to apex.

Variation. Males ( $\mathrm{n}=15$, including the holotype): TL 1.311.73 (1.50 \pm 0.10$)$, PL 0.45-0.66 (0.55 \pm 0.06$)$, PW 0.51-0.72
$(0.63 \pm 0.05)$, EL 0.86-1.07 (0.94 \pm 0.06$),$ EW 0.55-0.74 (0.67 \pm 0.05), GD 0.50-0.67 (0.60 \pm 0.04$)$, Ratios: PL/PW 0.73-0.92 (0.88 $\pm 0.05), \mathrm{EL} / \mathrm{EW} 1.29-1.56(1.42 \pm 0.07), \mathrm{EL} / \mathrm{PL} 1.52-2.06(1.72 \pm$ $0.16), \mathrm{GD} / \mathrm{EW}$ 0.86-0.95 (0.90 \pm 0.03$)$, TL/EW 2.13-2.38 (2.26 \pm $0.08)$. The specimens vary in size and coloration; fully pigmented adults display a dark brown color, while teneral adults are yellowish-brown. Frontoclypeal horn vary from short (minimum of $0.1 \mathrm{~mm}$ ) to long (maximum of $0.44 \mathrm{~mm}$ ). Anterior edge of pronotum varying from strongly produced, forming two rounded lateral lobes in large males, to weakly or not produced in small males, with anterior pronotal edge almost rounded (Fig. 9). Females ( $\mathrm{n}=16)$ : TL 1.27-1.72 (1.54 \pm 0.14$)$, 


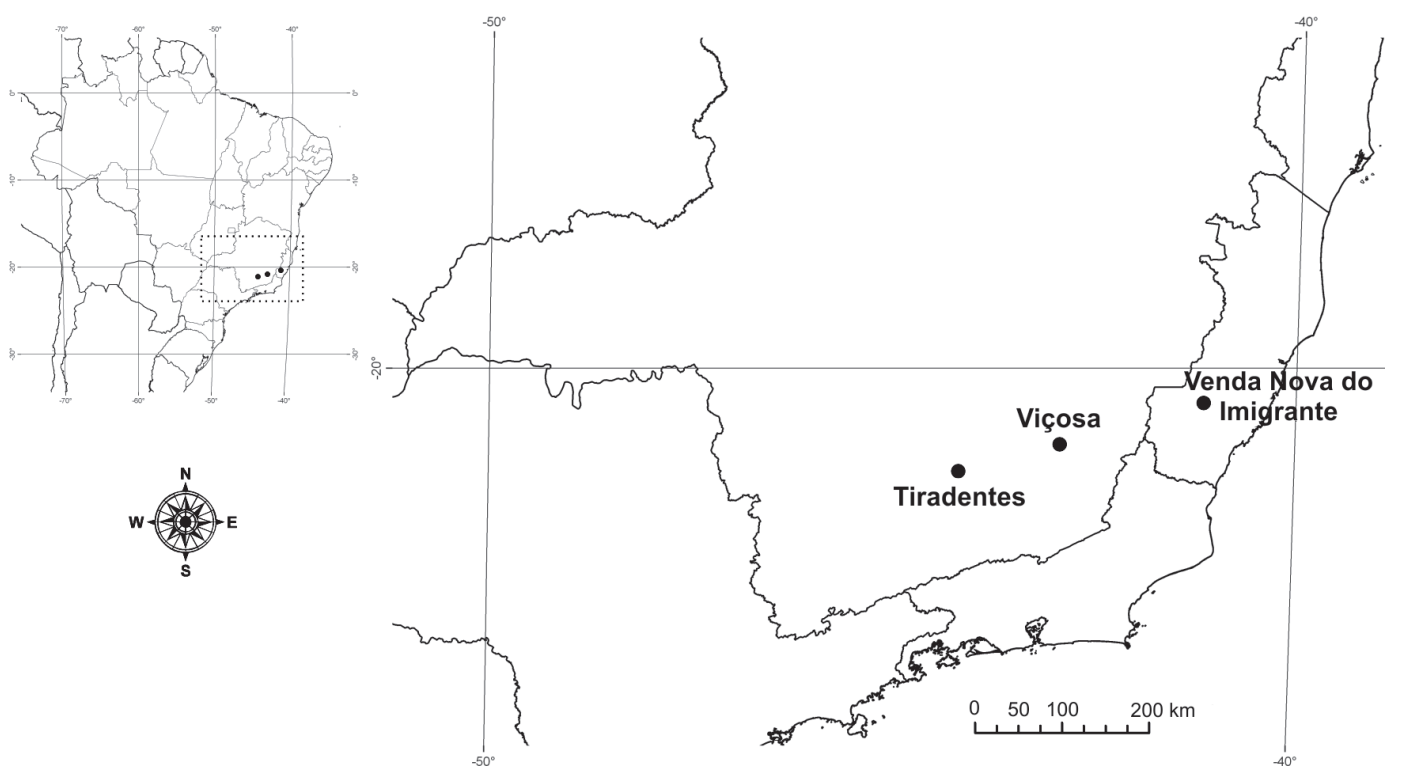

Figure 10. Distribution map for Ceracis zarathustrai sp. nov.

PL 0.46-0.63 (0.56 \pm 0.05$)$, PW 0.59-0.69 (0.62 \pm 0.04$)$, EL 0.68$1.12(0.97 \pm 0.10)$, EW 0.61-0.74 (0.68 \pm 0.04$)$, GD 0.56-0.69 (0.62 \pm 0.04). Ratios: PL/PW 0.74-0.97 (0.89 \pm 0.08$), \mathrm{EL} / \mathrm{EW}$ 1.0-1.56 (1.41 \pm 0.15$)$, EL/PL 1.15-2.11 (1.72 \pm 0.27$)$, GD/EW 0.87-0.97 (0.92 \pm 0.03$)$, TL/EW 1.87-2.45 (2.24 \pm 0.16$)$. Similar to males except in the following features: abdominal sex patch absent; head flat, dorsal punctation comparatively coarser; frontoclypeal ridge devoid of horn; anterior edge of pronotum rounded, not produced. Female terminalia with gonocoxites transversely divided into two parts; distal gonocoxite devoid of gonostyli; paraprocts shorter than gonocoxites together; proctiger short and broad, its opening near dorsal rim of vagina.

Type series. Brazil: male holotype (CELC) labeled: "BRASIL, MG, Viçosa, 05.vii.2012, Maddalena, I.S.C.P. leg. \ex Trametes sp. \Ceracis zarathustrai Pecci-Maddalena, SandovalGómez \& Lopes-Andrade HOLOTYPUS [red paper]". Paratypes: 25 male (14 measured) and 25 female (16 measured) paratypes, as follows: 8 males (6 CELC, including 1 dissected; $2 \mathrm{MCNZ}$ ) and 11 females (9 CELC, including 1 dissected; 2 MCNZ) “BRASIL, MG, Viçosa, 05.vii.2012, Maddalena, I.S.C.P. leg. \ex Trametes sp. \Ceracis zarathustrai Pecci-Maddalena, SandovalGómez \& Lopes-Andrade PARATYPE [yellow paper]"; 16 males CELC, including 1 dissected (5 measured) and 14 females CELC (5 measured) "BRASIL, MG, Tiradentes (APA São José), 12.vi.2012, Oliveira, E.H \& Yanai-Barduche, A leg. \ex Trametes sp. \Ceracis zarathustrai Pecci-Maddalena, Sandoval-Gómez \& Lopes-Andrade PARATYPE [yellow paper]", each additionally labeled "trans. Parcela fungo [printed] 3 C 1 [handwritten]", "trans. Parcela fungo [printed] 3 C 3 [handwritten]" and "dissected, 14.viii.2013"; 1 male (CELC, dissected) "BRASIL, ES,
Venda Nova do Imigrante, 2003, Vaz-de-Mello, F.Z. leg. \Ceracis zarathustrai Pecci-Maddalena, Sandoval-Gómez \& LopesAndrade PARATYPE [yellowpaper]".

Etymology. The new species is named in honour of Zarathustra, the protagonist of the book "Also sprach Zarathustra: Ein Buch für Alle und Keinen”, by Friedrich Nietzsche.

\section{DISCUSSION}

Ceracis zarathustrai sp. nov. resembles species of the $C$. furcifer group, like C. cornifer, C. cylindricus (Brèthes, 1922), C. hastifer (Mellié, 1849), C. monocerus Lawrence, 1967, C. simplicicornis, and C. unicornis Gorham, 1898, in which antennae have nine antennomeres and apex of the frontoclypeal horn of males is rounded, truncate or shallowly emarginated. These and C. zarathustrai sp. nov. have similar body shape, fine and scattered pronotal and elytral punctuation and a rounded or shallowly emarginate pronotal apex. Other two species of the C. furcifer group, C. ruficornis Pic, 1916 and C. furcifer possess these same features, but differ in the frontoclypeal horn of males usually deeply incised at apex, forming a short bifurcation, and antennae with eight antennomeres. Besides superficial similarities, C. zarathustrai sp. nov. differs from all species in the $C$. furcifer group in having a more elongate body and concave prosternum, and males with frontoclypeal horn subcylindrical (it is laminar in the $C$. furcifer group), with a conspicuous tuft of yellowish bristles at apex, anterior portion of pronotum produced forward, concealing the head when seen from above (except for the horn), and anterior pronotum edge shallowly emarginate at middle, forming two short lobes. 
We dissected and examined sclerites of the male terminalia of $C$. furcifer, C. cornifer, and C. ruficornis. In these species, the tegmen has a deep longitudinal emargination at apex forming two wide parallel lobes, with rounded or blunt apices; the penis is cylindrical with rounded apex; and the sternite VIII has a conspicuous, deep concave emargination at the middle of the posterior edge. In C. zarathustrai sp. nov. the sternite VIII has a shallow V-shaped emargination at the posterior edge (Fig. 6), the lateral lobes of tegmen are narrow and acute at apex and the penis has a triangular sclerotization at the middle of the apical portion (Fig. 7), features that resemble most those of species in the C. cucullatus group (see AnTunesCarvalho \& Lopes-Andrade 2011, 2013). The basal piece is subtriangular in C. ruficornis, C. furcifer, and C. zarathustrai sp. nov., but in the latter it has more closed angles. In C. cornifer, the basal piece is subrectangular, being very different from the other examined species.

Both C. furcifer group and C. zarathustrai sp. nov. occur in Polyporaceae s. str. host fungi. However, species of the $C$. furcifer group are most frequently found in basidiomes of Pycnoporus sanguineus (L.) Murrill, 1904 (Lawrence 1973, GumierCosta et al. 2003, Graf-Peters et al. 2011), a very common fungi occurring in open areas of tropical Brazil, seldom observed inside forests (C. Lopes-Andrade, pers. obs.). Therefore, because of the almost strict association of species of the C. furcifer group with $P$. sanguineus, they are more frequently found in open natural (e.g., in the Cerrado biome), rural and urbanized areas than in forests. In contrast, the few host records for $C$. zarathustrai sp. nov. were in Trametes sp. collected in forest remnants, without any record from open areas. It is possible that this ciid does not survive under the conditions of open areas and is depended upon hosts occurring only inside forests.

The continuous deforestation of the Atlantic Forest is possibly keeping populations of $C$. zarathustrai sp. nov. isolated in separate small forest remnants, thus the species can be seriously threatened. There are other ciids considered to be restricted to forests in the Neotropical region, as species of Falsocis Pic, 1916 and Phellinocis Lopes-Andrade \& Lawrence, 2005 (Lopes-Andrade 2007, Lopes-Andrade \& LaWrence 2005, 2011). It is important to note that we and our colleagues have collected ciids in the Atlantic Forest biome for more than a decade, but $C$. zarathustrai sp. nov. was found in only three remnants and never in open areas. It is necessary to evaluate the feeding habits of the species, obtain further biological information, and access its conservation status.

We conclude that, despite superficial similarities of males, Ceracis zarathustrai sp. nov. does not belong to the C. furcifer group. It' is possible that this ciid belongs to the C. cucullatus group or another species-group in the genus, but an assignment would be premature at this time because detailed information on male terminalia of most Ceracis species is not available yet.

\section{ACKNOWLEDGMENTS}

We wish to express our thanks to John F. Lawrence for the loan of specimens of several species of Ceracis, and to Ester H. Oliveira and Fernando Vaz de Mello for collecting specimens. Financial support was provided by Fundação de Amparo à Pesquisa do Estado de Minas Gerais (FAPEMIG: Universal, APQ-00653-12; Programa Mineiro de Pós-doutorado - PMPD II; postdoctoral grant to VES), Conselho Nacional de Desenvolvimento Científico e Tecnológico (CNPq: PROTAX 52/ 2010, 562229/2010-8; master degree grant to the senior author, 133969/2013-4; Universal, 479737/2012-6), Coordenação de Aperfeiçoamento de Pessoal de Nível Superior (CAPES: PVE CsF/CNPq 88881.030447/2013-01), Secretaria de Estado de Ciência, Tecnologia e Ensino Superior de Minas Gerais (SECTESMG), Projeto Floresta-Escola, and the Graduate Program in Entomology of the Federal University of Viçosa (UFV).

\section{LITERATURE CITED}

Antunes-Carvalho, C. \& C. Lopes-Andrade. 2011. Two new Neotropical species of Ceracis Mellié (Coleoptera, Ciidae) and redefinition of the cucullatus group. ZooKeys 132: 5164. doi: 10.3897/zookeys.132.1570

Antunes-Carvalho, C. \& C. Lopes-Andrade. 2013. Two invaders instead of one: the true identity of species under the name Ceracis cucullatus (Coleoptera: Ciidae). PLOS ONE 8 (8): e72319. doi:10.1371/journal.pone.0072319

Graf-Peters L.V.; C. Lopes-Andrade; R.M.B. Silveira; L.A. Moura; M.A. Reck \& F. Nogueira-de-SÁ. 2011. Host fungi and feeding habits of Ciidae (Coleoptera) in a subtropical rainforest in Southern Brazil, with an overview of host fungi of Neotropical ciids. Florida Entomologist 94 (3): 553566.doi:10.1653/024.094.0320

Gumier-Costa, F.; C. Lopes-Andrade \& A.A. Zacaro. 2003. Association of Ceracis cornifer (Mellié) (Coleoptera: Ciidae) with the bracket fungus Pycnoporus sanguineus (Basidiomycetes: Polyporaceae). Neotropical Entomology 32 (2): 359-360.

doi : 10.1590/S1519-566X2003000200026

LACORDAIRE, J.T. 1857. Histoire naturelle des insectes. Genera des Coléoptères ou exposé méthodique et critique de tous les genres proposés jusqu'ici dans cet ordre d'insectes. Paris, Librairie Encyclopédique de Roret, Tome IV.

LAWRENCE, J.F. 1967. Delimitation of the genus Ceracis (Coleoptera: Ciidae) with a revision of North American species. Bulletin of the Museum of Comparative Zoology 136: 91-144.

LaWrence, J.F. 1971. Revision of the North American Ciidae (Coleoptera). Bulletin of the Museum of Comparative Zoology 142 (5): 419-522.

LAWRENCE, J.F. 1973. Host preference in ciid beetles (Coleoptera: Ciidae) inhabiting the fruiting bodies of Basidiomycetes in North America. Bulletin of the Museum of Comparative Zoology 145: 163-212. 
Lopes-Andrade, C. 2007. Notes on Falsocis Pic (Coleoptera: Tenebrionoidea: Ciidae), with the description of an endangered Brazilian species. Zootaxa 1544: 41-58.

LoPes-ANDRADE, C. 2011. The first Strigocis Dury (Coleoptera, Ciidae) from the southern Neotropical region and a provisional key to world species. ZooKeys 81: 27-37. doi: 10.3897/zookeys.81.940

Lopes-Andrade, C.; M.S. Madureira \& A.A. Zacaro. 2002. Delimitation of the Ceracis singularis group (Coleoptera: Tenebrionoidea: Ciidae), with the description of a new Neotropical species. Dugesiana 9 (2): 59-63.

Lopes-Andrade, C. \& J.F. Lawrence. 2005. Phellinocis, a new genus of Neotropical Ciidae (Coleoptera: Tenebrionoidea). Zootaxa 1034: 43-60.

Submitted: 18.V.2014; Accepted: 06.IX.2014.

Editorial responsibility: Gabriel L.F. Mejdalani
Lopes-Andrade, C. \& J.F. LaWrence. 2011. Synopsis of Falsocis Pic (Coleoptera, Ciidae), new species, new records and an identification key. ZooKeys 145: 59-78. doi: 10.3897/ zookeys.145.1895

MelLié, J. 1849. Monographie de l'ancien genre Cis des auteurs. Annales de la Société Entomologique de France 6: 205274, 313-396.

Oliveira, E.H.; C. Lopes-Andrade \& J.F. LaWrence. 2013. Review of the Neotropical Ciidae (Insecta: Coleoptera) in the Cis taurus species-group. Arthropod Systematics \& Phylogeny 71 (3): 181-210.

Wick, M. 2010. GeoNames. Available online at http:// www.geonames.org [Accessed: 30/VII/2014] 